\title{
Trabajadores y organizaciones sindicales en México: del mutualismo artesanal a la Ley laboral obrera de Zacatecas (1910-1925)
}

Judith Alejandra Rivas Hernández/UPN Zacatecas y

René Amaro Peñaflores/UAZ

\section{Resumen}

Este artículo da cuenta de la formación de la clase obrera en Zacatecas, específicamente constituida por trabajadores industriales (operarios mineros, de las manufacturas y artesanos proletarizados) y por jornaleros agrícolas, quienes formaban parte de una estructura industrial y agropecuaria caracterizada por el atraso. De tales fracciones de trabajadores surgió un sector laboral cuya formación como clase social transitó por procesos de organización y movimientos sindicales consolidados mediante experiencias propias (huelgas), pero definidas por las facciones revolucionarias en lucha a partir de 1910 (villistas, carrancistas, obreristas) y, cuya culminación fue el establecimiento de instancias laborales como la junta de conciliación y arbitraje, el departamento del trabajo, la promulgación del Artículo 123 de la Constitución de 1917, la formación de la Cámara Obrera de Zacatecas y la expedición de la ley laboral local de 1925. En esta legislación se plasmaron los derechos laborales, salarios, contrato colectivo, organización sindical y movimientos huelguísticos. No obstante, con base en dicha legislación laboral y nuevas instancias de los trabajadores, apareció un control corporativo sindical anclado al partido político oficial.

Palabras clave: clase obrera, mutualistas-sindicatos, leyes laborales y corporativismo sindicalsindical.

"Workers and Unions in Mexico: From the mutual unions to the Zacatecas Labor Law (1910-1925)"

\section{Abstract:}

This article portrays the formation of the working class in Zacatecas, specifically constituted by industrial workers (mining workers, manufacturers and proletarian artisans) and agricultural laborers, who were part of an underdeveloped industrial and agricultural structure. From these fractions of workers arose a labor sector whose formation as a social class transited through organizative processes and creation of labour movements exercised through their own experiences (strikes), but defined by the revolutionary factions struggling after 1910 (Villistas, Carrancistas, obreristas). The establishment of labor bodies such as the 
conciliation and arbitration board, the labor departments, the promulgation of Article 123 of the Constitution of 1917, the formation of the Cámara Obrera de Zacatecas and the issuance of the local labor law of 1925 was the ending point of the formation of this working class. In this legislation, labor rights, salaries, collective bargaining agreements, union organization and strike movements were reflected. However, based on this labor legislation and new organizations of the workers, a corporate union control appeared anchored to the official political party.

Key words: working class, mutual-unions, labor laws and union corporatism.

Recibido: 10 de noviembre de 2017

Aceptado. 28 de marzo de 2018

\section{Introducción}

Entre finales del siglo XIX y 1910, en Zacatecas, con sus matices -como en otras partes del país en donde dominaban las relaciones económico-sociales capitalistas, los trabajadores estaban situados en una estructura social constituida por 1) Propietarios rurales (hacendados y rancheros), 2) trabajadores agrícolas (peones, medieros y aparceros), 3) empresarios (propietarios y banqueros) y comerciantes), 4) operarios mineros (barreteros, pepenadores, fundidores, salineros), 5) artesanos y operarios industriales (oficios mecánicos y obreros), 6) profesionistas (maestros, abogados, médicos, ingenieros, arquitectos), 7) empleados del gobierno y clérigos (burócratas, militares, sacerdotes), 8) empleados de establecimientos privados (administradores y trabajadores comerciales) y 9) trabajadores de diferentes ramas (transportes y comunicaciones, domésticos). ${ }^{1}$

Específicamente, los trabajadores industriales locales (operarios mineros y de las diversas manufacturas) formaban parte de una estructura industrial caracterizada por el atraso, pues la definían las fases extractivas mineras y de transformación básica sustentada en una gama de talleres artesanales y sólo operaban algunas unidades productivas manufacturera y de corte moderna. La producción minera local y el cambio en el modelo extractivo de los metales preciosos a los metales industriales en los años noventa del siglo

\footnotetext{
${ }^{1}$ Ciro F. S. Cardoso y Francisco G. Hermosillo, "Las clases sociales durante el Estado liberal de transición y la dictadura porfirista (1867-1910)", en Ciro F. S. Cardoso, Francisco G. Hermosillo y Salvador Hernández, De la dictadura porfirista a los tiempos libertarios (La clase obrera en la historia de México), México, IISUNAM/Siglo XXI Editores, 1980, pp. 46-52.
} 
XIX, los capitales extranjeros, la expansión de las vías férreas en la entidad (Ferrocarril Central y tranvías) y el uso de máquinas de vapor en los procesos productivos, amén de otras tecnologías modernas, no ayudaron a superar el atraso económico zacatecano, por el contrario, lo profundizaron. ${ }^{2}$

En este contexto, ¿quiénes eran los trabajadores locales de las industrias y del campo hacia 1910? ¿Tales trabajadores formaban la clase obrera en Zacatecas? Un primer acercamiento en términos históricos, nos permite decir que dicha clase obrera la formaban los antiguos artesanos que laboraban ahora como oficiales-operarios en los nuevos talleres libres y al seno de las unidades productivas manufactureras. Asimismo, la integraban los operarios mineros, textiles y los peones o jornaleros agrícolas. Se definían como hombres y mujeres que producían ciertos tipos de bienes y que por ello obtenían un jornal o salario para sobrevivir. ¿Formaban una clase social? Sí, a condición de concebir su posición en la estructura social no conceptualmente sino a partir de su situación o formación históricaconcreta. ${ }^{3}$ Ahora bien, ¿cómo estaban organizados laboralmente? Los procesos organizativos de los trabajadores locales entre 1910 y 1925 transitaron del mutualismo-cooperativismo a los primeros sindicatos que surgen tras las experiencias y acciones en defensa de sus derechos laborales, las cuales se diluyeron en las coyunturas político-militares revolucionarias. Dichos fines laborales pervivieron y derivaron en formas de organización sindicales más acabadas como la Cámara Obrera de Zacatecas en 1917, en el marco jurídico que rigió el Artículo 123 constitucional a nivel nacional y, un poco más tarde, en la ley reglamentaria local de dicho artículo en 1925.

\section{La problemática historiográfica sobre los trabajadores}

Clara E. Lida ${ }^{4}$ señala que tras los procesos independentistas hispanoamericanos el mundo del trabajo sufrió profundas rupturas (jurídicas, políticas, sociales y económicas). Del

\footnotetext{
${ }^{2}$ Armando Márquez Herrera et al., Historia de la cuestión agraria mexicana. Estado de Zacatecas (1530-1910), Tomo I, México, Juan Pablos/Gobierno del Estado de Zacatecas/CEHAM-UAZ, 1990, p. 146.

3 Jorge González Angulo y Roberto Sandoval Zarauz, "Los trabajadores industriales de Nueva España, 17501810”, en Enrique Florescano et al., De la colonia al imperio. La clase obrera en la historia de México, T. 1, 7a. Ed., México, Siglo XXI Editores/IIS-UNAM, 1996, p. 174.

4 Lida, E. Clara, "Trabajo, organización y protesta artesanal: México, Chile y Cuba en el siglo XIX”, en Artesanos en Hispanoamérica (Dossier), en Historia Social, Núm. 31, 1998, pp. 67-71.
} 
sector artesanal dominante caracterizado por la calificación del oficio y defensa del gremio, se transitó al trabajo libre y remunerado de diversas formas (contratación jornalera, subcontratación, trabajo a destajo). La nueva categoría laboral, el operario-artesano, paulatinamente descalificado laboralmente, proletarizado económicamente, se convierte en simple trabajador de las manufacturas y en operario-obrero de las fábricas modernas, mecanizadas y se ejercía una pronunciada división del trabajo. Del artesano-proletario, sin calificación, se pasaba en términos conceptuales a obrero de las manufacturas y de las nuevas industrias. En este contexto, la propia Lida, citando a Sonia Pérez y Carlos Illades ${ }^{5}$ (1998), sostiene que en México se dio el paso "de la asociación a la movilización y al conflicto", mediante las huelgas por aumentos de salario, mejoramiento de las condiciones de trabajo, entre ellas la reducción de la jornada laboral y la reglamentación del trabajo femenino e infantil. La ruptura social en el ámbito laboral culminó a finales del siglo XIX y principios del XX y se alimentó de las luchas de los trabajadores por la ciudadanía, de la noción del trabajo y del producto como propiedad, así como del boom mutualista y las diversas luchas organizativas obreras, ligados o al margen de las ideas socialistas y anarquistas. ${ }^{6}$

Jorge Basurto $^{7}$ sostiene que, en la segunda mitad del siglo XIX, la legislación iusnaturalista (Constitución de 1857 y las Leyes de Reforma) contribuyeron a alentar el movimiento obrero al proletarizarse o empobrecerse cada vez más el sector laboral. Al surgir el proletariado industrial, con él apareció la clase obrera mexicana y una incipiente lucha de clases a finales del siglo XIX, a pesar de la heterogeneidad de la composición del proletariado (artesanos, operarios mineros y manufactureros), hubo luchas espontáneas, aunque sin el uso sistemático de la huelga. En todo caso, el mutualismo y el cooperativismo fueron ineficaces y utópicos pues no representaron un peligro para el capital y Estado. Sin embargo, la influencia ideológica socialista y anarquista y el rol de los líderes como Zalacosta, Villanueva o los Flores Magón, fueron forjando una toma de conciencia “en sí y para sí”, necesaria para la formación de la clase obrera. De los trabajadores ferrocarrileros, mineros y operarios

\footnotetext{
${ }^{5}$ Sonia Pérez Toledo y Carlos Illades, "El artesanado textil en la Ciudad de México en el siglo XIX", en Historia Social 31, 1998, pp. 77-88. https://www.jstor.org/stable/40340677 (consulta 8 de octubre 2018). ${ }^{6}$ Clara E. Lida, "Trabajo, organización y protesta artesanal...”, p. 70.

${ }^{7}$ Jorge, Basurto, El Proletariado industrial en México (1850-1930), México, IIS-UNAM, 1975, pp. 7-38/141149.
} 
manufactureros, organizados en torno al Partido Liberal Mexicano (1906), surgió una ideología oposicionista al régimen porfirista, lo cual alentó la efervescencia obrera, sobre todo después de la caída del régimen.

En este mismo sentido, Juan Felipe Leal y José Woldenberg ${ }^{8}$ señalan que las primeras agrupaciones obreras son las mutualistas y las cooperativas, las cuales estaban constituidas en estructuras organizativas que eran propias del artesanado, pero que al mismo tiempo representaban el inicio del tránsito y el espacio de emergencia del proletariado industrial. Los autores señalan que, ante la falta de una reglamentación laboral específica, el proletariado se inclinó por instituir sociedades de ayuda mutua, como importantes bases apoyo de las luchas huelguísticas como las cajas de socorro mutuo se convirtieron que se convertían en fondos de resistencia y de sobrevivencia de los trabajadores en coyunturas de lucha laboral o de crisis. Entonces, las mutualistas son la "fachada que encubre y disfraza las sociedades secretas, empeñadas en una práctica sindical. $" 9$ En esta misma línea, Juan Felipe Leal, ${ }^{10}$ al analizar a los operarios textiles (artesanos y obreros), sostiene que sus niveles altos de combatividad de estos trabajadores, por las numerosas huelgas que estallan entre $1881 \mathrm{y}$ 1895, “dieran los primeros pasos para estructurar federaciones de asociaciones por rama industrial, cual fue el caso de la Federación Obrera, que se constituyó en el mes de octubre de 1884...” Así entre estos operarios-obreros se desarrolló una auténtica cultura obrera, con sus "tradiciones, conocimientos y formas de relación" compartidas. ${ }^{11}$

Por su parte, Alejandro García ${ }^{12}$ sostiene que los trabajadores mexicanos, en el contexto de finales del siglo XIX y primeras décadas del siglo XX, desarrollaron un movimiento obrero "caracterizado por la incapacidad de constituir en su seno proyectos políticoorganizativos de carácter masivo y anticapitalista, o bien sindicatos mayoritarios que, a pesar

\footnotetext{
${ }^{8}$ Juan Felipe Leal y José Woldenberg, "Orígenes y desarrollo del artesanado y el proletariado industrial en México: 1867-1914” en Revista Mexicana de Ciencias Políticas y Sociales, núm. 80, México, FCP y S-UNAM, 1975, pp. 131-159.

${ }^{9}$ J. Leal y J. Woldenberg, "Orígenes y desarrollo del artesanado...".

${ }^{10}$ Juan Felipe Leal, Del mutualismo al sindicalismo en México: 1843-1910, México, El Caballito, 1991.

${ }^{11}$ J.F. Leal, Del mutualismo..., pp. 60-61.

${ }^{12}$ Alejandro García, "Apuntes históricos sobre la clase obrera en México", en Bibliografía para el estudio de la clase obrera en México, Universidad de Murcia, octubre de 1982, pp. 213-228. revistas.um.es/analeshc/article/viewFile/107531/102181 (consulta 8 de octubre 2018).
} 
del corporativismo inherente, en algún momento hubieran cuestionado radicalmente por su propia dinámica, la legitimidad y estabilidad de la sociedad imperante."13 Es difícil compartir estos planteamientos de García, pues los trabajadores mexicanos permanentemente implementaron proyectos políticos y forjaron ideologías alternativas al momento histórico en el que se movieron. Por ejemplo, la que planteaba la "República del Trabajo", como un momento en cual las relaciones laborales armónicas, de solidaridad y de ayuda mutua dominaban la vida social, lo cual significaba un proyecto social como finalidad, por utópico que fuera. Asimismo, el proceso del primer socialismo mexicano, matizado de asociacionismo mutual, armonía y solidaridad, se pasó a la etapa de la lucha de clases: “Justamente fue el anarquismo de inicios del siglo XX el que imprimió un giro discursivo al socialismo mexicano al abandonar el planteamiento de la armonía social en favor de la lucha de clases." 14

Como sea, las “huelgas revolucionarias” (Cananea y Río Blanco, 1906-1907) dirigidas por el Partido Liberal Mexicano y otros movimientos organizativos y huelguísticos de 1911, son previos y explican la formación de la Casa del Obrero Mundial (1912) y la huelga general (1916), de la que habla García y que, si bien fue fallida, adquirió repercusiones nacionales en muchos sentidos, además, a la postre, precipitó la formación de la CROM en 1918 y otros sindicatos independientes. ${ }^{15}$

John M. Hart ${ }^{16}$ nos habla de un moderno movimiento obrero que comenzó hacia 1860 , compuesto por "obreros artesanales", en cuyas filas militan diversas tendencias laborales: radicales, moderadas, socialistas y anarquistas. Dichas tendencias plateaban su vinculación con el Estado y otras establecían límites de independencia con los intereses políticos. El autor da cuenta de los importantes esfuerzos organizativos de los trabajadores, del GCOM y el primer Congreso Obrero (50 mil participantes y 100 sindicatos); de las luchas, huelgas y rol de los trabajadores moderados y radicales. Respecto a estos últimos, la influencia ideológica

\footnotetext{
${ }^{13}$ A. García, “Apuntes históricos...”, pp. 213-228.

${ }^{14}$ Carlos, Illades, Las otras ideas. Estudio sobre el Primer Socialismo en México, 1850-1935, México, Era, UNAM, 2008, p. 258.

15 A. García, "Apuntes históricos".

16 John Mason, Hart, “Los Obreros Mexicanos y el Estado, 1860-1931”, en Nexos, núm. 37, enero 1981, pp. 21-27.
} 
que recibieron del anarquismo, se concretizó en La Social ("la sociedad secreta anarquista”) y después en el Partido Liberal Mexicano ("44 unidades guerrilleras clandestinas y varios clubs”). Las experiencias de lucha artesanal-obrera culminaron con el PLM (1906), la Casa del Obrero Mundial (1912), las huelgas masivas de los años de 1907 a 1910 y otros "choques callejeros violentos, manifestaciones" y revueltas que abarcaron hasta 1916. En todas ellas se transitaba de una "variedad flexible de posturas pragmáticas, idealistas e ideológicas", mutuales, gremialistas y anarquistas, “que llevaron al desarrollo al sindicalismo obrero". En suma, dice el autor: "Durante el período de 1910 a 1916 los obreros se organizaron según su experiencia del siglo XIX y del PLM. Triunfaron en la movilización de sindicatos de trabajo en una escala sin precedentes. Fracasaron en sus esfuerzos alcanzar mayor poder porque fundamentalmente quedaron subordinados dependientes de la maquinaria militar constitucionalista, de dirección burguesa. Las contradicciones económicas entre ellos y el régimen provocaron una serie de huelgas, algunas de las cuales fueron las más exitosas en la historia del país."

John Womack Jr. ${ }^{18}$ hace referencia al hecho de que la primera escritura de la historia sobre los obreros era aquella en el que "el sujeto no existía", pues se trataba de artesanos y sus mutualistas, pero los sindicatos no eran tales. Fue hasta la Revolución, con la COM, que se ofreció un sujeto histórico por estudiar, además una política laboral y la sindicalización obrera. Luego, apareció una historiografía de los trabajadores "de calidad", con un sentido social, político y cultural. Una "historia obrera real", con sus "movimientos en la que los sujetos son sindicatos (si bien aún no con esta denominación) "a partir de la mitad del siglo XIX y a lo largo del Porfiriato, ya con el nombre de sindicatos durante la Revolución". Empero, a pesar de la importancia de este nuevo saber, revisten en él dos deficiencias: 1) la que tiene que ver con lo empresarial, los análisis acerca del capital, la mano de obra y los mercados vinculados a la industria particular en la que operaba un sindicato. No hay estudios sobre la tecnología, ni microanálisis de las instalaciones mecánicas, del equipo existe de las mismas, ni de la división del trabajo que se requería en la planta mecánica y menos de las

\footnotetext{
${ }^{17}$ J. M. Hart, "Los Obreros Mexicanos...," pp. 21-27.

${ }^{18}$ John Womack Jr., "Historia obrera mexicana", 1998, en Nexos, https://www.nexos.com.mx/?p=8719 (consulta 10 de octubre 2018).
} 
relaciones materiales de producción, en las cuales ocurría la posición estratégica que ocupaban los artesanos fabriles, como trabajadores calificados frente a los obreros no calificados y que significaba un "poder técnicamente determinado en el trabajo" y que gozaba de mejores salarios. Esto explica no sólo el dominio de dichos obreros estratégicos al seno del sindicato, sino el 2) porqué de la existencia de pequeños sindicatos locales que buscaban preservar su independencia, misma que se ponía en riesgo en las organizaciones laborales de corte nacional o confederal. (Womack Jr., 1988) El autor, en este sentido, señala que "los trabajadores industrial y técnicamente estratégicos hicieron movimientos obreros asombrosos", con base en sus luchas que efectuaron entre 1906 y 1916, mediante "huelgas políticamente independientes y ampliamente inmovilizantes en los ferrocarriles y, de manera asombrosa en 1916, en la principal compañía eléctrica, Luz y Fuerza del Centro, los trabajadores mexicanos aseguraron una amplia gama de derechos en la nueva constitución mexicana de 1917." Es decir, los trabajadores al ejercer su posición estratégica para procesos técnicos de producción o para otros propósitos organizativos y sindicales, actúan, apelan a su "agencia", echan a andar su estrategia y con ello su agencia. ${ }^{19}$

En suma, la formación de la clase obrera mexicana se inscribe en el amplio mundo del trabajo y de las luchas obreras, allí en donde las mutualistas fueron las organizaciones dominantes, pero regidas y toleradas por el orden liberal. El derecho a la libre asociación estuvo limitada frente a la falta de una legislación laboral, la cual apareció hasta la Revolución mexicana (1910-1920). Por ello el conflicto social estuvo vedado al seno de las organizaciones de trabajadores: estaban prohibidas las discusiones políticas y religiosas. "De hecho, cuando lograron confederarse y adquirir mayor fuerza, la tentación de utilizarlas con fines partidarios acabó con ellas. Ese fue fracaso común de los congresos obreros de 1876 y 1879, y de la Casa del Obrero Mundial." ${ }^{20}$

\footnotetext{
19 John Womack Jr., Posición estratégica y fuerza obrera. Hacia una nueva historia de los movimientos obreros, México, Fondo de Cultura Económica/Fideicomiso Historia de la Américas/El Colegio de México, 2007, pp. 72-76.

${ }^{20}$ Carlos Illades, "Prologo", en Carlos Illades y Mario Barbosa (coords.), Los trabajadores de la ciudad de México, 1860-1950, México, El Colegio de México/UAM-Unidad Cuajimalpa, 2013, p. 12.
} 


\section{Los orígenes de la clase obrera en Zacatecas}

Desde este contexto historiográfico sobre el movimiento organizativo de los trabajadores mexicanos situamos el planteamiento de la clase obrera zacatecana. Tal como ya señalamos, los artesanos, los operarios mineros y manufactureros dominaban la escena laboral de la segunda mitad del siglo XIX en Zacatecas. Respecto a los operarios mineros, un primer acercamiento al estado de su situación, específicamente en cuanto a empleo permanente y sus salarios, encontramos lo siguiente:

[...] el número de trabajadores empleados en las actividades mineras experimentó fluctuaciones significativas de uno a otro año en las dos últimas décadas del periodo. Esa cifra pasó de 8089 en 1898 a 21847 en 1901, para caer luego en forma continua a 8726 en 1903 y, más aún, a 3895 en 1905, tras lo cual se recuperó levemente para sumar 9670 trabajadores en $1907 .^{21}$

Los salarios de los operarios mineros revistieron también una diferenciación entre una empresa y otra. Pero el incremento salarial en coyunturas de auge minero no garantizó que las condiciones de vida de los trabajadores mejoraran, pues "los riegos de accidentes no aminoraron con el progreso técnico, y los daños sufridos no solían ser compensados con indemnizaciones o seguros para las familias desamparadas."22 Además, la amenaza del desempleo siempre estuvo latente por la introducción de maquinaria moderna y nuevos métodos productivos. Armando Márquez Herrera sostiene que:

[...] el engendro más doloroso y aberrante que dio a luz la minería fue el desempleo, ocasionado por el abandono de numerosas zonas mineras que no estuvieron en capacidad de incorporarse al proceso de cambio o que se sedujeron tempranamente al capital transnacional modernizante [...] Si bien el desempleo favoreció a la minería moderna por su impacto depresor en los salarios y en la capacidad de negociación de los trabajadores, incrementó la miseria, la despoblación en ciertas zonas, los flujos migratorios, etcétera, polarizando ingresos, clase y regiones. ${ }^{23}$

\footnotetext{
${ }^{21}$ Sandra Kuntz Ficker, "La República restaurada y el Porfiriato”, op. cit., pp. 137-138.

${ }^{22}$ C. Illades y M. Barbosa (coords.), Los trabajadores de la ciudad de México, p. 138.

${ }^{23}$ Armando Márquez Herrera, "Las transformaciones de la minería zacatecana durante el porfiriato", en Dolores Ávila Herrera y Rina Ortiz (comps.), Minería regional mexicana. Primera reunión de Historiadores de la Minería Latinoamericana (IV), México, INAH, 1994, p. 63.
} 
Entonces, frente al atraso industrial, desempleo, bajos salarios, miseria, migración, despoblación y accidentes de trabajo constantes, entre 1911 a 1923 los operarios mineros locales estallaron varias huelgas, en Mazapil, Sombrerete y Fresnillo.

A las malas condiciones laborales de los operarios mineros se sumaban las de las otras fracciones de trabajadores. En 1910 tenemos registros de que laboraban 10811 obreros del sector industrial; 104315 del sector agropecuario y 15970 del sector servicios. ${ }^{24}$ Cabe señalar que, en el año de 1912, en el contexto de la contienda electoral por el gobierno del estado, el padrón electoral del primer cuartel de la ciudad de Zacatecas registraba ciertas cantidades de operarios mineros: un total de 41 operarios fluctuantes de edad entre los 20 y 63 años. ${ }^{25}$ De ellos sólo el 29.26 \% sabía leer y escribir, y en consecuencia, cerca del el 71 $\%$ eran analfabetos. Los indicadores sobre la capacidad lectora de ellos son los posibles indicios de hasta dónde por medio de la lectura de la prensa y folletos pudieron tener acceso a información de propaganda de corte anarquista, socialista, liberal y, aún, del catolicismo social.

Otras ocupaciones formaban la base social y técnica-laboral de la ciudad de Zacatecas para 1912. Eran mayoría los comerciantes, empleados públicos y particulares. Aparecían también los albañiles, jornaleros, carpinteros, encuadernadores, panaderos, veladores, talabarteros, cargadores, tipógrafos, herreros, lecheros, zapateros, sastres, un tenedor de libros, pintores, un telegrafista, un mecánico, dulceros, un aguador, filarmónicos, un peluquero y un obrajero. ${ }^{26}$

Sobre los jornales o salarios de los trabajadores éstos casi no aumentaron respecto al periodo de la república restaurada, se mantuvieron en 50 centavos diarios a oficiales y 20 centavos a aprendices. En el sector minero, la tendencia fue al incremento, pues pasó de 62 centavos diarios en los años setenta a 87 centavos entre 1900 a 1910. Aunque también

\footnotetext{
${ }^{24}$ Sandra Kuntz Ficker, "La República restaurada y el Porfiriato", op. cit. [Cuadro VII.2], p. 128.

${ }^{25}$ Biblioteca Pública Mauricio Magdaleno, Sección Hemerográfica, Colección Zacatecas, Periódico Oficial de Gobierno, Tomo XLVIII, Núm. 14, febrero, Municipalidad de Zacatecas, 1912, pp. 213-215. (En adelante BPMM-HZ).

${ }^{26}$ Biblioteca Pública Mauricio Magdaleno, Sección Hemerográfica, Colección Zacatecas, Periódico Oficial de Gobierno, Tomo XLVIII, Núm. 14, febrero, Municipalidad de Zacatecas, 1912, pp. 213-215.
} 
variaron dichos salarios entre empresas mineras e incluso al seno de las mismas. En Mazapil se pagaba a los operarios hasta un peso como jornal mínimo, en cambio en el partido de Zacatecas el jornal menor era de 50 centavos. En la empresa minera El Edén un obrero podía ganar desde 37 centavos a 6 pesos diarios, frente a los 312 a 3000 pesos anuales que percibían los administradores de las minas. ${ }^{27}$ En este contexto de diversificación salarial, los operarios mineros se organizaran para luchar por la reivindicación de sus derechos. Se tienen registros de que, en 1911, “tres de las principales compañías mineras del estado enfrentaron movimientos huelguísticos y desde ese año hasta 1916 la ocupación del territorio por parte de grupos bandoleros o revolucionarios hizo inciertas [todavía más] las condiciones de producción." 28

\section{Facciones revolucionarias y pensamiento obrerista}

Como sabemos, en Zacatecas la lucha armada que comenzó en 1910 tuvo dos fases claramente distinguibles: 1) la revolución maderista en contra del antiguo régimen de Díaz, es decir, de corte político y 2) la revolución social propugnada por los sectores populares, para cambiar sus condiciones de trabajo, en el campo, en las minas, como en la ciudad. La primera faceta no representó una guerra civil generalizada en el estado; no tuvo causa propia que no fueran los postulados maderistas. No obstante, un poco antes de los Tratados de Ciudad Juárez (1911), alcanzó la lucha un amplio dominio en varias regiones de la entidad. Tras la renuncia de Díaz, los logros políticos fueron escasos, se limitaron al cambio de gobernador y de algunos funcionarios porfiristas. Sin embargo, confirmamos que el efecto más significativo fue el impacto en la sociedad civil: en la prensa combativa, caracterizada por su diversidad ideológica y en el surgimiento de nuevas organizaciones políticas, sindicatos y partidos. ${ }^{29}$

\footnotetext{
${ }^{27}$ Sandra Kuntz Ficker y Luis Jáuregui, "Entre el pasado y el presente”, en Jesús Flores Olague et al., La Fragua de una leyenda (Historia Mínima de Zacatecas), México, Noriega, 1997, p. 154.

${ }^{28}$ Sandra Kuntz Ficker, "La Revolución Mexicana (1913-1920)", en Jesús Flores Olague et al., Zacatecas: Historia breve, $2^{\mathrm{a}}$ edición, El Colegio de México, FCE, México, 2011, p. 169.

${ }^{29}$ Sandra Kuntz Ficker y Luis Jáuregui, “Entre el pasado y el presente”, op. cit., pp. 166-167.
} 
Aquí hubo una continuidad y ruptura en cuanto a los procesos asociacionistas provenientes del porfiriato. Por ejemplo, la mutuo-cooperativa "Obreros Libres" de Antonio Chávez Ramírez, en la coyuntura revolucionaria recuperó su protagonismo al adoptar el maderismo como bandera ideológica, aunque esto no les haya permitido, a su presidente, y a otros candidatos liberales, triunfar en la elección gubernamental de 1912. Lo contrario ocurrió con el Círculo de Obreros Católicos, mutualista que postuló a José Guadalupe González, quien triunfó como gobernador, lo cual le permitió al partido católico consolidar su posición y conquistar varios cargos de representación popular.

Respecto a las ideas sindicalistas, éstas en 1911, matizaban los ideales "socialistas" pues planteaban la emancipación del proletariado -mediante la conformación de una confederación nacional de trabajadores-, aunque continuaban añorando la felicidad obrera, la fraternidad universal y el progreso. Quizá la importancia total de estos ensueños socialistas radicaba en la proclama en pro de la unión obrera, la lucha social y la libertad. Dicha proclama esencialista rayaba en el socialismo romántico -conciencia social y de espíritu proletario- aún con tintes decimonónicos que planteaban que la alternativa era la organización de sólidas asociaciones socialistas confederadas, frente a un capitalismo emergente y rapaz, causante de la ruina laboral. ${ }^{30}$

El golpe de Estado de Victoriano Huerta en febrero de 1913, marcó la faceta social de la revolución local pues revistió un carácter popular con la asunción de causas propias: poner fin al cacicazgo, cerrar las tiendas de raya, reducir los impuestos, llevar a cabo elecciones democráticas y plantear la defensa de la autonomía municipal. ${ }^{31}$ Por ello cuando los militantes maderistas -Pánfilo Natera, Eulalio Gutiérrez, Gertrudis Sánchez, Santos y Félix Bañuelos, Enrique Estrada-, hicieron suyo el Plan de Guadalupe y se incorporaron a las filas constitucionalistas, articularon la cuestión social con las nuevas determinaciones políticas revolucionarias. Los constitucionalistas zacatecanos pronto dominaron las ciudades y regiones principales del estado con excepción de la capital. Natera, al mando de la División

\footnotetext{
30 “Ayer se celebró en Zacatecas un mitin socialista. Gran número de obreros concurrió a escuchar la doctrina Salvadora", en El Anti-reeleccionista. Órgano del Club Anti-reeleccionista "José Luis Moya", Zacatecas, lunes 21 de agosto de 1911 (BPMM-H).

${ }^{31}$ S. Kuntz Ficker y L. Jáuregui, “Entre el pasado y el presente”, p. 168.
} 
del Centro, conocedor de la importancia que representaba para la Revolución la toma ciudad de Zacatecas, con sus propios recursos militares, asedió y bloqueó los abastos de hombres y pertrechos de ejército federal; empero, el triunfo definitivo culminó, como se conoce con detalle, con la participación de la División del Norte al mando de Francisco Villa en 1914 (La Toma de Zacatecas).

El triunfo constitucionalista definió el destino de la revolución política: el aparato estatal y militar porfirista se destruyó. Pero, tras el triunfo revolucionario se profundizó la escisión de los principales caudillos y facciones revolucionarias: carrancistas, villistas y zapatistas. En Zacatecas ocurrió un proceso similar: huestes carrancistas (Roque y Enrique Estrada); aliados al villismo y más tarde al constitucionalismo (Pánfilo Natera) o fieles siempre a Villa (Santos Bañuelos y Tomás Domínguez) que fueron combatidos y acusados de bandoleros. En este contexto de luchas políticas y militares locales y de inestabilidad constante, de disputas entre los grupos políticos, organizaciones obreras y agraristas, Enrique Estrada llegó al poder del estado a finales de 1916. Luego, al ser declarado gobernador constitucional en julio de 1917 y durante el tiempo que duró en el poder, hasta 1919, apoyó las diversas acciones organizativas del sector obrero. Se alió a líderes obreros de la talla de Tomás Leal, José Inés Medina y Francisco Vela para que ellos directamente mediaran en los conflictos laborales del estado, a través del Departamento de Trabajo y Previsión Social, dependiente del gobierno estatal. ${ }^{32}$ En efecto, las nuevas organizaciones laborales eran promovidas por las autoridades políticas locales, pero en conjugación con el esfuerzo de actores que había forjado un pensamiento con una clara visión social orientada a resolver el "problema social", el "problema obrero".

Así pues, el pensamiento obrerista de Estrada se despliega a favor de los trabajadores en la forma cómo operaban instancias laborales como el Departamento de Trabajo y Previsión Social y la Junta de Conciliación y Arbitraje (1919); ambas instancias

\footnotetext{
32 En 1920 estalló la huelga en la Compañía minera The Mazapil Coorper Company, de Concepción del Oro, pero que fue "solucionada felizmente" mediante el arbitraje ejercido por José Inés Medina, "alto empleado del departamento de Justicia del propio Gobierno y delegado de éste... quien con acierto y atingencia pudo lograr que... la Compañía minera aumentara el jornal de sus obreros... mientras se expide la Ley del Trabajo, que está elaborando el Gobierno del Estado." La Opinión. Órgano del Club "Trinidad García de la Cadena", Zacatecas, 24 de octubre de 1920 (BPMM-H).
} 
gubernamentales tenían como objetivo mediar en los conflictos laborales, establecer

resoluciones sobre los aumentos de salarios a $\operatorname{los}$ obreros $^{33}$ y que sus responsables visitaran los centros de trabajo para prevenir futuros conflictos obrero-patronales. ${ }^{34}$

Por su parte, los campesinos (jornaleros agrícolas) formaron también sus sindicatos, con el objetivo primordial de hacer valer la Ley Agraria del Estado decretada en 1917 por el propio gobernador Enrique Estrada quien había impulsado la creación de fraccionamientos rurales. Así, aparecieron en 1918 la Sociedad de Obreros "Unión y Concordia", que luchaba en Saín Alto por la tierra; el Sindicato de Labradores, Defensores de la Tierra (La Zacatecana), el Gran Sindicato "Regeneración Agrícola" (Santa Elena, Ojocaliente). ${ }^{35}$

No obstante, la visión y práctica obrerista de Enrique Estrada entró en conflicto con la política anti-obrerista de Carranza, lo que generó la ruptura política entre Zacatecas y el primer gobierno constitucional nacional. En abril de 1920, Estrada se adhirió al Plan de Agua Prieta obregonista, determinación que incidió en el proceso laboral-organizativo local, por ejemplo, generó una ruptura al seno de la Cámara Obrera de Zacatecas.

\section{La Cámara Obrera de Zacatecas}

Esta instancia sindical, la más importante de la época, se formó en 1917 y su composición laboral se nutrió de "un gran número de obreros perteneciente a diferentes gremios, con el objeto de constituir una Cámara que proteja y ayude, por los medios posibles, al obrero." ${ }^{36}$ Parecía que los fines de la Cámara Obrera seguían anclados a la tradición de

\footnotetext{
33 "Informe rendido por el C. Gobernador Gral. Estrada... al Congreso del Estado", 16 de septiembre de 1919, pp. 10-11 (BC-UAZ)

34 “Departamento del Trabajo y Previsión Social”, en Alba Roja, Semanario Obrero de Doctrina, Información y Combate, 17 de octubre de 1920 (BPMM-H).

35 "200 obreros organizados en Saín Alto, Zac., bajo el nombre 'Unión y Concordia' se han unido a la Cámara Obrera de esta ciudad", en Zacatecas, 20 de Julio de 1918; "Con los elementos proletarios del Rancho 'La Zacatecana', se ha constituido el 'Sindicato de Labradores, Defensores de la Tierra", Zacatecas, 27 de Julio de 1918; y "Un Gran Sindicato con el significativo nombre de 'Regeneración Agrícola' se ha establecido en Santa Elena, Zacatecas, 21 de septiembre de 1918, en Alba Roja. Semanario Obrero de Doctrina, Información y Combate, 1918 (BPMM-H).

36 "Quedó definitivamente constituida la Cámara Obrera en Zacatecas", en Adelante. Seminario de Información. Órgano de la "Unión Zacatecana de Empleados Particulares, S.M.C.", Zacatecas, octubre 28 de 1917 (BPMM$\mathrm{H})$.
} 
corte mutual, adoptar "medidas indispensables" para enfrentar la crisis generada por el movimiento armado, la miseria y el hambre, pero el hecho de que aparezca en la mesa directiva personajes como José Inés Medina, permite plantear que los fines de la asociación ya eran plenamente de tipo sindicales y aun con tintes anarco-socialistas. ¿Quién era José Inés Medina? José Enciso Contreras sostiene que Medina, como carpintero y minero, desde muy joven se vinculó al movimiento artesanal-obrero y fue fundador, antes de 1905, de la Mutualista Benito Juárez, que sabemos que, en determinadas coyunturas electorales, operaba en realidad como un Club Político. ${ }^{37}$

La primera mesa directiva de la Cámara Obrera, fue presidida por Tomás Leal y el cargo de secretario recayó en José Inés Medina. La instancia sindical aglutinó a algunas organizaciones mutualistas y a la mayoría de los sindicatos recién formados por la nueva política de clase que oscilaba entre la "Escila anarquista a la Caribdis del caudillismo". ${ }^{38}$ Es decir, la Cámara Obrera operó como un frente sindical que se movía en torno a los peligros que implicaba que los trabajadores se alejaran del "monstruo anarquista", que planteaba el total aislamiento con el poder, pero al mismo tiempo con el riesgo de caer inevitablemente en el otro "monstruo", mediatizador y corporativo, en la redes del Estado. En otro sentido, el dilema laboral oscilaba en la recuperación de un capital social sustentado en la amplia tradición de lucha organizativa obrera local -pues la cámara era heredera del grupo Acción Cultural Sindicalista, de tendencia socialista- y entre la nueva circunstancia política impuesta por los intereses caudillistas.

Específicamente, los objetivos de la Cámara Obrera radicaban en la "protección y ayuda" para los diferentes gremios de obreros en ella reunidos, lo que implicaba adoptar "las medidas indispensables para evitar que la crisis actual aumente más y más, al grado que tengamos por la miseria y el hambre [que padecemos], que presenciar otra horrible epidemia

\footnotetext{
${ }^{37}$ José Inés Medina tuvo relación con la Casa del Obrero Mundial y colaboró en la creación de la Confederación de Obreros "Luz y Fuerza", en la Acción Cultural Sindicalista, en la Cámara Obrera y en el grupo Alma Obrera. Actuó también en el terreno agrario, pues se destacó como impulsor del fraccionamiento de los latifundios, en el marco de la Ley de Estrada que creaba los fraccionamientos rurales en 1917. Participó adicionalmente en la fundación, en 1918, de la Confederación Regional Obrera Mexicana (CROM). José Enciso Contreras, "Invasiones de tierra en Zacatecas", pp. 19-20, inédito.

${ }^{38}$ Pablo González Casanova, En el primer gobierno constitucional (1917-1920) (La clase obrera en la historia de México), México, IIS-UNAM/Siglo XXI Editores, 1980, pp. 18-19.
} 
que nos azotó atrozmente el año pasado." 39 Otros objetivos consistían en "aliviar en algo la precaria situación por que atravesamos, señalando y combatiendo los males que engendra la avaricia comercial insaciable en detrimento siempre de la clase menesterosa, y proponer y llevar a cabo lo que a su juicio sea factible para conjurar la crisis económica que aqueja al pueblo. ${ }^{40}$ En suma, sus propósitos sindicales se resumían en la frase: "Contra todos los abusos" laborales.

Ahora bien, la base social de la Cámara Obrera la constituían básicamente campesinos, jornaleros, agricultores y algunos operarios mineros. ${ }^{41}$ Dicha base social se consolidó cuando los trabajadores de Saín Alto se anexaron a ella después de formar su sindicato "Unión y Concordia". En este tenor se integraron otros sindicatos: Sindicato de "Oficios Varios" de Zacatecas, Grupo "Femenil de Estudios Sociales" de Zacatecas, Grupo "Acción Cultural Sindicalista" de Zacatecas, Sindicato Agrícola "Tierra Libre" de Palmillas; Gran Liga Obrera, de Concepción del Oro; Sindicato de Agricultores "Defensores de la Tierra" de la Zacatecana; Sindicato Agrícola "Obreros de Ojocaliente"; "Centro Sindicalista de Agricultores Emancipados" de El Carro; Sociedad de Obreros "Unión y Concordia” de Saín Alto; Sindicato de "Pastores y Agricultores Libres" de Trancoso; Sociedad de Obreros Campesinos, de Fresnillo; Colonia Agrícola “Aquiles Serdán” de Río Grande; Sindicato Agrícola "Amor y Libertad" de las Blancas; Sindicato de Agricultores "Patria Humanitaria" de San José del Saladillo, y Gran Sindicato “ Regeneración Agrícola” de Santa Elena. ${ }^{42}$

La lucha por el poder a nivel nacional -Carranza, De la Huerta y Obregón- y local Estrada, Moreno-, generó una inestabilidad política que incidió al seno de las organizaciones obreras, entre éstas y las mesas directivas mutuo-cooperativistas. Las contiendas entre los

\footnotetext{
${ }^{39}$ BPMM-HZ, "Quedó definitivamente constituida la Cámara Obrera de Zacatecas", en Adelante. Semanario de Información órgano de la "Unión Zacatecana de Empleados Particulares", 2 época, núm. 5, 28 de octubre de 1917, Zacatecas.

${ }^{40}$ BPMM-HZ, "Los obreros zacatecanos dan los primeros pasos para lograr el propósito de sindicarse" en Revolución Social. Semanario Político órgano del Partido Liberal Constitucionalista Zacatecano, Año 1, Tomo 1, núm. 56, Domingo 11 de noviembre de 1917, Zacatecas.

${ }^{41}$ BPMM-HZ, Periódico Oficial de Gobierno, Tomo XLVIII, Núm. 14, 10 de febrero, Municipalidad de Zacatecas, 1912. (Cuartel de la ciudad no. VIII).

42 BPMM-HZ, "Más de 4000 obreros organizados en el estado, tendrán representación en las próximas elecciones de la Mesa Directiva de la Cámara Obrera", en Alba Roja. Órgano de la Cámara Obrera de Zacatecas, Año 1, núm. 36, 21 de septiembre de 1918, Zacatecas.
} 
distintos grupos económicos locales (Cámara de Comercio) y las instancias políticosindicales de corte liberal, anarco-socialistas (Alba Roja), católicos (El Amigo del Obrero) y los promotores-defensores de la reforma agraria (semanario Tierra), se dio en la prensa política y obrera. ${ }^{43}$

En este contexto de lucha ideológica frontal y abierta, aparecieron escisiones al seno de la Cámara Obrera, pues los nexos de ésta con la CROM la obligaron a participar en la formalización del Partido Laboral de Luis N. Morones en 1919. Los partidarios a la CROM (Confederación Regional Obrero de México) salieron de la cámara y formaron el grupo "Emancipación"; los que se quedaron en la Cámara Obrera de Zacatecas fueron acusados de radicales, pero se mantuvieron activos en la lucha ideológica a través de su medio de difusión "Alba Roja", que ya operaba desde 1918 como un "Semanario Obrero de Doctrina, Información y Combate". Más tarde, en 1923, constituyeron el Grupo Sindicalista Alma Obrera.

\section{La Ley Reglamentaria del Artículo 123 de Zacatecas en 1925 (Decreto 317)}

A pesar de que el Artículo 123 precisaba con claridad los derechos sobre el trabajo en México, se estipuló que se legislara sobre la materia en cada estado, para que éstos contaran con su propia reglamentación laboral: "El Congreso de la Unión y las Legislaturas de los Estados deberán expedir leyes sobre el trabajo, fundadas en las necesidades de cada región, sin contravenir a las bases siguientes, las cuales regirán el trabajo de los obreros, jornaleros, empleados, domésticos y artesanos, y de una manera general todo contrato de trabajo. ${ }^{44}$

En Zacatecas, la reglamentación sobre los derechos de los trabajadores se dio hasta 1925, cuando el gobernador Aureliano Castañeda (1923-1925) emitió el Decreto no. 317. Es cierto que, en la Ley Agraria de 1917, que declaró legal la pequeña propiedad rural, se registró la categoría trabajadores agrícolas, de aquellos que accedieron a las tierras repartidas, y que Ley Reglamentaria de 1925 no dejó fuera. Resaltamos este hecho pues se tienen

\footnotetext{
43 "El actual movimiento social que se opera, [respuesta categórica al reaccionario pasquín El Amigo del Obrero]", en Alpha. Quincenal de doctrina, información y combate, 4 de febrero de 1919, BPMM-H.

44 Constitución Política de los Estados Unidos Mexicanos de 1917, p. 75.
} 
noticias de la formación de Colonias Agrícolas en lugares como Ojocaliente, las cuales desde 1917 fueron visitadas por algunos miembros de la Cámara Obrera de Zacatecas. Además, los trabajadores agrícolas representaron una parte crucial de la mano de obra de Zacatecas.

Estas colonias agrícolas al igual que las colonias obreras quedaron reguladas por el Artículo 123, fracción XII, el cual se estipuló que:

\begin{abstract}
En toda negociación agrícola, industrial, minera o cualquiera otra clase de trabajo, los patronos estarán obligados a proporcionar a los trabajadores, habitaciones cómodas e higiénicas, por las que podrán cobrar rentas que no excederán del medio por ciento mensual del valor catastral de las fincas. Igualmente deberán establecer escuelas, enfermerías y demás servicios necesarios a la comunidad. Si las negociaciones estuvieren situadas dentro de las poblaciones, y ocuparen un número de trabajadores mayor de cien, tendrán la primera de las obligaciones mencionadas. ${ }^{45}$
\end{abstract}

La ley general establecía que los patrones debían fundar escuelas, prestar habitaciones higiénicas y enfermerías. En Zacatecas, se hicieron esfuerzos legales por dar cumplimiento cabal a dicho deber, pues el Decreto 317 o Ley Reglamentaria del Artículo 123, partía desde una idea precisa sobre quiénes eran los trabajadores y por supuesto también definió la conceptualización de los patrones o empresarios. Los primeros se constituían por "todas las personas que, por remuneración fija, aleatoria o variable, o por una participación en los beneficios, prestan sus servicios personales a otra, como los obreros, buscones, empleados, domésticos y aprendices... [Así como] los anteriores los arrendatarios y aparceros..."46

Los segundos, los dueños de los medios de producción, eran: “...la sociedad o corporación pública o privada, propietarios o contratistas de la obra, explotación, industria, etc., en el que el trabajo se preste." ${ }^{47}$ Bajo este esquema, entonces, el patrón es aquel individuo-propietario de la unidad productiva en donde se labora o produce algún bien o servicio.

\footnotetext{
${ }^{45}$ Constitución Política, p. 77.

${ }^{46}$ HDNM, Periódico Oficial de Gobierno del Estado de Zacatecas, año VII, Tomo XIX, nueva época, núm. 29, miércoles 7 de octubre, 1925, p. 471.

${ }^{47}$ HDNM, Periódico Oficial de Gobierno del Estado de Zacatecas, año VII, Tomo XIX, nueva época, núm. 29, miércoles 7 de octubre, 1925, p. 471.
} 
Las unidades productivas, ya sean talleres, industrias o minas demandaban ser supervisadas por inspectores de los Consejos Consultivos. De ello trata el título segundo de la ley citada, en donde se da cuenta de los organismos institucionales creados para la "pacífica" relación entre trabajo y capital. Estos instrumentos jurídicos se institucionalizaron con el establecimiento del Departamento de Trabajo, las Juntas Municipales de Conciliación y la Junta Central de Conciliación y Arbitraje.

Un aspecto laboral que queremos enfatizar, es el Contrato de Trabajo, ${ }^{48}$ como convenio o pacto oral o escrito donde las partes aceptan ciertas obligaciones y derechos sobre una materia determinada. En la Reglamentación se refería al establecimiento de obligaciones entre las partes que no estuvieran fuera de la ley, así como la duración de un año en perjuicio de los trabajadores. La falta de cumplimiento de este contrato de trabajo sólo obligaba a las partes de manera civil sin el uso de la coacción. En esta Reglamentación estatal podemos encontrar una ligera línea de distinción entre un contrato individual de trabajo y uno colectivo. ${ }^{49}$ En el Artículo 28, se hacen una serie de especificaciones sobre la nulidad del contrato referente a las jornadas inhumanas de trabajo, las indemnizaciones, además de las garantías de que el trabajador tuvo para pertenecer a un determinado sindicato, corporación, asociaciones profesionales con el objeto de "defender y promover sus intereses profesionales." 50

\footnotetext{
${ }^{48}$ Para este periodo no existe una definición clara y concisa de este tipo de relación laboral entre patrón y trabajador. Su ambigüedad tiene que ver con la etapa porfirista y prerrevolucionaria pues la legislación sobre las relaciones laborales estaba destinada esencialmente a disciplinar la fuerza de trabajo a los requerimientos propios del trabajo asalariado. No es de extrañar que para este periodo sólo existan leyes sobre accidentes de trabajo y la abstinencia de consumo de embriagantes. La conceptualización sobre el contrato de trabajo y posteriormente contrato "colectivo" de trabajo, surgió en el contexto de legitimación revolucionaria como una de las primeras respuestas de los gobiernos para proporcionar el tan anhelado equilibrio entre el capital y el trabajo. Graciela Bensusán, El modelo mexicano de regulación laboral, México, Plaza y Valdés/UAM/ Friedrich Ebert Stiftung, 2000, p. 74.

${ }^{49} \mathrm{El}$ derecho mexicano sobre el trabajo es entendido como un derecho social de clase contenido en el contrato colectivo; es una institución típica de negociación como instancia de la lucha que se gesta entre las clases. Un principio de este derecho es el reconocimiento de carácter fundamental de las asociaciones de trabajadores y profesionales que se impone por la fuerza de la asociación sindical y la huelga. Cuando los trabajadores de una empresa se agrupan en sindicatos y soliciten la celebración de un contrato colectivo de trabajo, el patrón no tiene otra opción más que aceptarlo. Tatiana Coll et al, Lucha obrera en México. La visión de sus líderes y conceptos fundamentales, México, Editorial Popular de los Trabajadores, 1983, p. 195.

${ }^{50}$ HDNM, Periódico Oficial de Gobierno del Estado de Zacatecas, año VII, Tomo XIX, nueva época, núm. 31, miércoles 14 de octubre, Zacatecas, Zacatecas, 1925, p. 502.
} 
Otro rubro importante de la Reglamentación es el referente a la higiene y seguridad en el trabajo. Aquí se especificaba la necesidad de los trabajadores por laborar en espacios salubres y seguros para la prevención de los accidentes en el uso de las maquinarias, instrumentos o materiales de trabajo. Ello alude a los obreros u operarios mineros en sí. El patrón se obligaba a sostener un personal médico y los útiles indispensables que prestaran los debidos auxilios a las víctimas de accidentes. Estos accidentes si causaban la muerte del operario u obrero proporcionaban a la familia el poder acceder a una indemnización por parte del empresario.

Cabe señalar lo relacionado con las garantías que el gobierno mediante la Reglamentación ofreció a los trabajadores zacatecanos consistió en definir los servicios generales que todo centro o negociación agrícola o minera debía tener. Es decir, los baños, lavaderos, lavabos, comedores, inodoros y agua potable, siempre que este servicio no haya sido otorgado por el Ayuntamiento u Autoridad Municipal.

En aspectos referentes al trabajo realizado, en el Artículo 42 se planteaba que la jornada diurna máxima sería de seis horas para los jóvenes mayores de doce años y menores de dieciséis y de siete para las mujeres. El caso de las mujeres trabajadoras es notorio en esta legislación ya que se disponía para ellas el no desempeño de trabajos físicos con esfuerzo considerable durante los tres meses anteriores al parto, sin que en ningún motivo se rescindiera el contrato de trabajo o convenio por esta circunstancia. El punto esencial es documentar si este derecho en realidad se ejerció. A las mujeres obreras se les concedió el disfrute del descanso durante las dos semanas anteriores al parto y el mes siguiente con la percepción integra de su salario al mismo tiempo el derecho de conservar el empleo. El periodo de lactancia en la Ley de 1925, se estimó de un año en donde las mujeres obreras pudieron acceder o no a descansos extraordinarios cada día de media hora cada uno para amamantar a los hijos. Sin embargo, a pesar de estos beneficios para las mujeres, éstas si eran casadas sólo podían acceder al contrato de trabajo si y sólo sí contaban con la autorización de sus maridos. 
En asuntos del salario la Reglamentación fue clara en el Artículo 49: para trabajo igual debe corresponder salario igual. Y éste estaba supeditado a la duración de la jornada de trabajo que era de ocho horas para la diurna, siete para la nocturna y de siete y media si era mixto. Con estas jornadas de trabajo, también se le asignó descanso y vacaciones al trabajador, éste tenía derecho a descansar un día a la semana, así mismo podía suspender labores el $1^{\circ}$ de mayo y el 16 de septiembre de cada año. En el Artículo 68 se dispuso que toda clase de trabajadores disfrutara de un periodo de 10 días de vacaciones durante el año laboral con goce de sueldo y de acuerdo con el reglamento respectivo de la empresa.

En materia de organización sindical y movimientos huelguísticos, la Reglamentación reconocía a la huelga como un acto concertado colectivo por el cual un grupo de trabajadores suspendía la ejecución de un servicio convenido. ${ }^{51}$ Se consideraba que una huelga era ilícita cuando los huelguistas cometieran actos violentos contra personas o propiedades. Una huelga podía ser legal sólo si se cumplían ciertas condiciones jurídicas: el dar aviso al presidente del Ayuntamiento con diez días de anticipación a la fecha señalada para la suspensión de los trabajadores, si es un asunto estatal se le comunicaba al Ejecutivo al mando al mismo tiempo que a la Junta de Conciliación.

La huelga no fue el único mecanismo de resistencia reconocido por la Reglamentación pues los paros laborales también fueron materia de legislación. Un paro en este sentido, fue definido como la suspensión temporal o definitiva de los trabajos de cualquier negociación o negociaciones por acuerdo del patrono o por causa de fuerza mayor. Podía ser lícito cuando el exceso de producción hiciera necesario la suspensión del trabajo para mantener los precios en el límite costeable, por fuerza mayor como por ejemplo incendios, explosiones, terremotos, guerra, derrumbes o epidemias y por la falta de materia prima.

Para estos efectos de resistencia laboral, los sindicatos fueron los organismos de intervención necesarios para el funcionamiento del equilibrio entre el capital-trabajo. En el Título quinto de la Reglamentación los sindicatos son entendidos como una organización o

\footnotetext{
${ }^{51}$ Artículo 69. En HDNM, Periódico Oficial de Gobierno del Estado de Zacatecas, año VII, Tomo XIX, nueva época, número 35, miércoles 28 de octubre, Zacatecas, Zacatecas, 1925, p. 566.
} 
asociación profesional para los efectos mismos de la Ley, además podía ser toda aquella agrupación tanto patronal como de trabajadores, constituida exclusivamente para el estudio, desarrollo y defensa de intereses comunes. ${ }^{52}$

A los sindicatos se les otorgó una entidad jurídica en donde adquirieron derechos y obligaciones para comparecer en justicia para la defensa de los intereses de un colectivo de asociados o el interés personal de cada uno de sus miembros, todo ello porque en realidad los sindicatos representan un "equilibrio" entre el capital y el trabajo. Para lograr estos objetivos debían contar por lo menos con cinco miembros mayores de edad. Su personalidad jurídica se les reconoció por medio de la presentación de una carta de patente y por un acta privada suscrita por los fundadores. Esta acta constitutiva debía contar con los nombres, apellidos y domicilio de los miembros, la denominación y objeto de la asociación, el nombramiento de una junta directiva y los estatutos. Además, los sindicatos podían coaligarse entre sí, es decir, hacer uniones, federaciones, confederaciones o cámaras de trabajo a las cuales se les aplicarían las mismas disposiciones jurídicas. ${ }^{53}$

\section{Reflexiones finales}

La formación de la clase obrera en México y sus movimientos asociacionistas y de lucha laboral se desarrollan a partir de la intensa proletarización de los artesanos-operarios manufactureros y de sus experiencias de lucha asociacionista, primero como mutualistas y luego como sindicato. Si bien es cierto, no hay una continuidad directa entre ambas instancias laborales si apareció una tendencia que marcó el tránsito de la ayuda mutua, la armonía y la solidaridad entre sí a la lucha socio-sindical por los derechos de los trabajadores. En Zacatecas, el mutualismo fue muy activo y prevaleció hacia la década de 1910, pero las experiencias huelguísticas, los múltiples accidentes de trabajo en las empresas mineras dominadas por el capital externo y el papel de las facciones revolucionarias, amén de la “agencia” de líderes como José Inés Medina, Tomás Leal, Francisco Vela, J. Guadalupe Escobedo, Teodoro Ramírez, Úrsulo García Arizmendi, Juan Nupomuceno Carlos,

\footnotetext{
${ }_{52}^{52}$ HDNM, Periódico Oficial de Gobierno del Estado de Zacatecas., miércoles 28 de octubre de 1925, p. 568.

${ }^{53}$ Idem (Artículos 85-94).
} 
Guillermo Rubio Cabrera y otros, definieron la organización y la emergencia de instancias sindicales fuertes como la Cámara Obrera en 1917. ${ }^{54}$

Así pues, las disposiciones laborales que recuperamos de la Ley Reglamentaria del Artículo 123 representan un legado de luchas laborales mutuales-sindicales que cobran relevancia durante la Revolución mexicana, plasmándose en derechos constitucionales. En efecto, como sostiene Pablo González Casanova, la Constitución de 1917 se convirtió en una Constitución social por las acciones de caudillos, líderes laborales y el nuevo pacto social que se impuso a la clase obrera. El Estado revolucionario mexicano, brindaba los derechos laborales, mediante un "poder arbitral que regulara los cambios sociales sin comprometerse demasiado con caudillos campesinos y líderes obreros, a modo de mantener una clase empresarial necesaria, y, por encima de todos, 'el poder supremo del gobierno de la República'.,55

¿En qué medida eso ocurrió en Zacatecas? En el plano jurídico observamos con claridad los derechos de los trabajadores, quiénes eran éstos, sus salarios, los patrones, los contratos colectivos, la higiene y seguridad laboral, los servicios generales, los derechos de las mujeres trabajadoras, el derecho a la sindicalización y a la huelga. En fin, un conjunto de derechos gremialistas y sociales que mostraban cómo se configuraba el Estado de bienestar laboral sustentado en una constitución social y en una ideología laborista cada vez más hegemónica.

Es conocido que el contexto actual es desfavorable para el sindicalismo mexicano, tras el avasallamiento del Estado neoliberal sobre los derechos laborales. Por ello se requiere recuperar el rol de los sindicatos no sólo como instancias de defensa de los derechos de los trabajadores, con un carácter autogestionario y autónomo, sino también como organismos de la sociedad civil que posibiliten una contra hegemonía fundamental para la negociación y el cambio. La idea sobre el pragmatismo sindical y con un sentido de la oportunidad política, ${ }^{56}$

\footnotetext{
${ }^{54}$ René Amaro Peñaflores y Judith Alejandra Rivas Hernández, De los procesos de consolidación y ruptura de las mutualistas a los primeros sindicatos de Zacatecas (1870-1926), México, UAZ/CONACYT, 2015, p. 310.

55 Pablo González Casanova, En el primer gobierno constitucional, op. cit., pp. 7-23.

${ }^{56}$ Pablo González Casanova, El primer gobierno constitucional, op. cit., p. 13.
} 
corporativizada y anclada a un partido político o a ciertos intereses ajenos a los trabajadores, que tanto daño han hecho a la lucha social, debe erradicarse. Preservar el actual statu quo sindical no sólo pone en riesgo las conquistas históricas laborales -prestaciones, salarios, derecho a la salud y recreación- contenidas aún en algunos contratos colectivos, sino aun el trabajo mismo, aquél que "volvió humana a nuestra especie, cada vez más humana". 57 Reivindicar la credibilidad sindical implica replantear el derecho positivo constitucional vigente que rige y brinda los derechos sociales y recuperar el derecho de gentes sustentado en un iusnaturalismo que sanciona los derechos de asociación laboral como derechos naturales del hombre y las mujeres. Se requiere pues reconstruir el tejido laboral y social en favor de la construcción de sindicatos modernos, democráticos y activos sustentados en los valores históricos legados por los trabajadores del siglo XIX y principios del siglo XX, tales como la solidaridad, la fraternidad y el bien común, que no el individualismo egoísta y frívolo.

A más de cien años del Artículo 123 constitucional y de la nueva reforma laboral de $2017,{ }^{58}$ que endurece y escamotea los derechos de los trabadores, la pregunta obligada es: ¿Dónde quedaron el papel protagónico de los sindicatos locales o federados y las posiciones estratégicas que ejercían los obreros al seno de las plantas productivas? Las respuestas a tales cuestiones platean nuevos retos a los trabajadores y a sus organizaciones laborales, consistentes en reivindicar derechos y una ideología autogestionaria e independiente, que responda nuevamente al ideal colectivista, al libre derecho a la sindicalización y a los mecanismos que imponen el outsourcing (subcontratación) neoliberal.

\section{Bibliografía}

\footnotetext{
${ }^{57}$ John Womack Jr., Posición estratégica y fuerza obrera, op. cit., p. 34.

58 "[...] hoy en día una nueva reforma laboral (febrero de 2017), cuan "monstruo jurídico", no sólo lesiona el Artículo 123 constitucional, sino busca cancelar los derechos de los trabajadores conquistados históricamente: afectar el derecho humano al trabajo, cancelar los contratos colectivos, imponer un mecanismo de contratación criminal denominado outsourcing y erradicar el derecho de huelga y la libertad de asociación". Judith Alejandra Rivas Hernández y René Amaro Peñaflores, "Karl Marx y los sindicatos en el contexto de la reforma laboral de 2017", en Rubén Ibarra Reyes et al., La obra perdurable de Marx, México, Unidad Académica de Ciencias Sociales-UAZ, 2018 [CD], pp. 89-90.
} 
Amaro Peñaflores, René y Judith Alejandra Rivas Hernández, De los procesos de consolidación y ruptura de las mutualistas a los primeros sindicatos en Zacatecas (1870-1926), México, UAZ, CONACYT, 2015.

Rivas Hernández, Judith Alejandra y René Amaro Peñaflores, "Karl Marx y los sindicatos en el contexto de la reforma laboral de 2017", en Rubén Ibarra Reyes et al., La obra perdurable de Marx, México, Unidad Académica de Ciencias Sociales-UAZ, 2018 [CD], pp. 86-94.

Basurto, Jorge, El Proletariado Industrial en México (1850-1930), México, IIS-UNAM, 1975.

Bensusán, Graciela, El modelo mexicano de regulación laboral, México, Plaza y Valdés/ UAM/Friedrich Ebert Stiftung, 2000.

Cardoso, Ciro F. S. y Francisco G. Hermosillo, "Las clases sociales durante el Estado liberal de transición y la dictadura porfirista (1867-1910)", en Ciro F. S. Cardoso, Francisco G. Hermosillo y Salvador Hernández, De la dictadura porfirista a los tiempos libertarios (La clase obrera en la historia de México), México, IIS-UNAM/Siglo XXI Editores, 1980, pp. 7-100.

Coll, Tatiana, et al., Lucha obrera en México. La visión de sus líderes y conceptos fundamentales, México, Editorial Popular de los Trabajadores, 1983.

Constitución Política de los Estados Unidos Mexicanos de 1917

Enciso Contreras, José, “Invasiones de tierra en Zacatecas”, Inédito, pp. 19-20.

García, Alejandro, “Apuntes históricos sobre la clase obrera en México", en Bibliografía para el estudio de la clase obrera en México, Universidad de Murcia, octubre de 1982, pp. 213-228.

González Casanova, Pablo, El primer gobierno constitucional (1917-1920). La clase obrera en la historia de México, México, Siglo XXI Editores, UNAM, 1984.

González Angulo, Jorge y Roberto Sandoval Zarauz, "Los trabajadores industriales de Nueva España, 1750-1810", en Enrique Florescano et al., De la colonia al imperio. La clase obrera en la historia de México, T. 1, 7ª . Ed., México, Siglo XXI Editores/IISUNAM, 1996, pp. 173-238.

Hart, John Mason, “Los Obreros Mexicanos y el Estado, 1860-1931”, en Nexos, núm. 37, enero 1981, pp. 21-27.

Illades, Carlos, Las otras ideas. Estudio sobre el Primer Socialismo en México, 1850-1935, México, Era, UNAM, 2008. 
Illades, Carlos, "Prologo", en Carlos Illades y Mario Barbosa (coords.), Los trabajadores de la ciudad de México, 1860-1950, México, El Colegio de México/UAM-Unidad Cuajimalpa, 2013, pp. 9-17.

Kuntz Ficker Sandra y Luis Jáuregui, "Entre el pasado y el presente”, en Jesús Flores Olague et al., La Fragua de una leyenda (Historia Mínima de Zacatecas), México, Noriega, 1997, pp. 166-167.

Kuntz Ficker, Sandra: "La Revolución Mexicana (1913-1920)", en Jesús Flores Olague et al., Zacatecas: Historia breve, $2^{\mathrm{a}}$ edición, El Colegio de México, FCE, México, 2011, pp. 154-171.

Márquez Herrera, Armando, Historia de la cuestión agraria mexicana. Estado de Zacatecas (1530-1910), Tomo I, México, Juan Pablos/Gobierno del Estado de Zacatecas/CEHAM-UAZ, 1990.

Márquez Herrera, Armando, "Las transformaciones de la minería zacatecana durante el porfiriato", en Dolores Ávila Herrera y Rina Ortiz (comps.), Minería regional mexicana. Primera reunión de Historiadores de la Minería Latinoamericana (IV), México, INAH, 1994, pp. 59-75.

Leal, Juan Felipe y José Woldenberg, “Orígenes y desarrollo del artesanado y el proletariado industrial en México: 1867-1914" en Revista Mexicana de Ciencias Políticas y Sociales, núm. 80, México, FCP y S-UNAM, 1975, pp. 131-159.

Leal, Juan Felipe, Del mutualismo al sindicalismo en México: 1843-1910, México, El Caballito, 1991.

Lida, E. Clara, “Trabajo, organización y protesta artesanal: México, Chile y Cuba en el siglo XIX”, en Artesanos en Hispanoamérica (Dossier), en Historia Social, Núm. 31, 1998, pp. 67-75.

Pérez Toledo, Sonia y Carlos Illades, "El artesanado textil en la Ciudad de México en el siglo XIX”, en Historia Social 31, 1998, pp. 77-88. https://www.jstor.org/stable/40340677

Womack John Jr., "Historia obrera mexicana", 1998, en Nexos, https://www.nexos.com.mx/?p=8719

Womack John Jr., Posición estratégica y fuerza obrera. Hacia una nueva historia de los movimientos obreros, México, Fondo de Cultura Económica/Fideicomiso Historia de la Américas/El Colegio de México, 2007.

\section{Fuentes}

Biblioteca Pública Mauricio Magdaleno-Sección Hemeroteca (BPMM-H). Hemeroteca Digital Nacional de México (HDNM). 